\title{
Selective perception by dynamic touch
}

\author{
CLAUDIA CARELLO and MARIE-VEE SANTANA \\ Center for the Ecological Study of Perception and Action \\ University of Connecticut, Storrs, Connecticut \\ and \\ GREGORY BURTON \\ Seton Hall University, South Orange, New Jersey
}

\begin{abstract}
Perceiving the length of a rod by dynamic touch is tied to the inertia tensor $I_{i j}$, a quantification of its resistance to rotational acceleration. Perception of the portion extending in front of the grasp has previously been ascribed to decomposing one component of $I_{i j}$ by attention. The tensorial nature of dynamic touch suggests that this ability must be anchored wholly in the tensor. Three experiments show that perceived partial length is a function of two components of the tensor, one tied primarily to magnitude and the other tied primarily to direction, whereas perceived whole length is a function of a magnitude component alone. Dynamic touch is characterized in terms of a haptic perceptual instrument that softly assembles to exploit $I_{i j}$ differently depending on the intention, producing 1:1 maps that are appropriately scaled for each intention.
\end{abstract}

Selective attention is marked by the ability to respond to a subset of physically and physiologically available information that is appropriate for an intention to perceive a particular stimulus dimension. The degree of "success" at attention might be construed in terms of the degree to which putatively irrelevant dimensions of information influence or interfere with the perceiver's evaluation of the requested dimension. Relatedly, the degree of interference from dimensions that are unattended can be taken as indicators of processes that must be engaged in order to perceive the attended dimension. Although the bulk of data on attention comes from vision and audition, there are examples from touch as well. For example, it has been noted (e.g., Gibson, 1966) that a person using a tool to explore a surface receives information about both the handtool contact and the tool-surface contact but generally attends to the latter.

The kind of selective attention that has been demonstrated in dynamic or effortful touch will provide our focus. Gibson (1966) drew a distinction between dynamic touch, which entails muscular exertion in moving or stabilizing an object, and haptic touch, which involves the articulation of joints and limb segments. For example, grasping a rod somewhere along its length to wield or simply hold it requires muscular torque to counter the rotational forces brought about by the mass distribution of the rod. A number of experiments have shown that whether

The research reported here was supported by Grant SBR 93-09371 from the National Science Foundation. A preliminary report of Experiments 1 and 2 was presented to the Eighth International Conference on Perception and Action in July 1995 in Marseilles, France. The authors thank Chris Pagano and Elliot Saltzman for many helpful discussions. Correspondence should be addressed to C. Carello, CESPA, U-20, 406 Babbidge Road, University of Connecticut, Storrs, CT 06269-1020 (e-mail: cespal@uconnvm.uconn.edu). the rod is being wielded freely or simply held with minimal movement, perception of the rod extent in front of the hand-in particular, how far one could reach with that portion-is possible (e.g., Burton \& Turvey, 1991; Solomon \& Turvey, 1988; Solomon, Turvey, \& Burton, $1989 \mathrm{~b}$ ) and seems to be unaffected by characteristics of the rod behind the hand (e.g., whether or not it has an attached mass). These early examinations of perceived partial length stand in contrast to investigations of perceived whole length, which find it to be influenced by characteristics of the rod both in front of and behind the grasp. Whereas perception by dynamic touch generally has been understood in terms of the inertia tensor $I_{i j}$-a quantification of an object's resistances to rotational acceleration in different directions (Fitzpatrick, Carello, \& Turvey, 1994; Pagano, Kinsella-Shaw, Cassidy, \& Turvey, 1994; Solomon \& Turvey, 1988; Turvey \& Carello, 1995; see the next section for a discussion)-selective perception has been couched in terms of an ability to decompose a component of that tensor so as to direct attention to the mass distribution in front of the hand (Burton \& Turvey, 1991; Solomon et al., 1989b).

The notion of decomposing a tensor component is not without difficulty. As noted by its proponents, there are an infinite number of potential ways to split a given component into portions (Burton \& Turvey, 1991; Solomon \& Turvey, 1988; Solomon et al., 1989a; see Neisser \& Becklen, 1975, for a similar decomposition puzzle in visual selective attention). Consequently, the aforementioned investigations into selective perception by dynamic touch were reasonably circumspect on this point, noting that perceivers act "as if" they can decompose a component into fore and aft portions, perhaps exploiting directional strains of the tissues at the wrist. But to be consistent with the general strategy of anchoring dynamic touch in $I_{i j}$, what is needed is a way to direct attention that is sim- 
ilarly tensor based. Recent elaborations of the tensor framework suggest how this might be accomplished. We will show that the directionality needed for perceiving partial length is in $I_{i j}$. This hypothesis will be tested in three experiments.

\section{The Role of the Inertia Tensor in Perceiving Magnitudes and Directions: Perceived Partial Length Should Be a Function of Moments and Products of Inertia}

When the hand and arm are engaged in exploratory and performatory activities such as wielding an object, torques on the part of the muscles and motions on the part of the object are time-varying. They are linked, however, by a time-invariant quantity, the inertia tensor, $I_{i j} . I_{i j}$ is a $3 \times 3$ symmetric matrix. The symmetry means that the three numbers below the diagonal equal the three numbers above the diagonal. Consequently, an object's mass distribution can be captured in six components-three moments of inertia $\left(I_{x x}, I_{y y}, I_{z z}\right)$ on the diagonal and three products of inertia $\left(I_{x y}, I_{y z}, I_{x z}\right)$ off the diagonal. Whereas the moments are the resistances to rotational acceleration about the three orthogonal axes, the products are the resistances in directions perpendicular to these rotations and reflect the asymmetry of the mass distribution (Figure 1). The tensor components are conventionally calculated with respect to a rectangular coordinate system $O_{x y z}$ anchored in the wrist ${ }^{2}$ :

$$
\begin{aligned}
& I_{x x}=m\left(y^{2}+z^{2}\right)+m r^{2 / 4}+m L^{2 / 12,} \\
& I_{y y}=m\left(x^{2}+z^{2}\right)+m r^{2 / 4}+m L^{2 / 12,} \\
& I_{z z}=m\left(x^{2}+y^{2}\right)+m r^{2} / 2, \\
& I_{y z}=-m y z,
\end{aligned}
$$

where $m$ is the rod mass, $r$ is the rod radius, $L$ is the rod length, and $x, y$, and $z$ are perpendicular distances along the axes to $O_{x y z}$ (given that $x=0$ in Figure 1, we have shown the only nonzero product). These are the equations for homogeneous solid cylinders. The first term in each, in accordance with the parallel axis theorem, reflects the fact that $O$ is not at the center of mass (CM); the remainder is $I_{i j}$ through the CM (which $=0$ for $I_{y z}$ ).

Of course, an infinite number of three-axis sets could be so anchored and the components of $I_{i j}$ will differ for each. The sets are related, however, by a transformation law (see, e.g., Borisenko \& Tarapov, 1979) and there is an invariant set that is independent of $O_{x y z}$. The so-called diagonalized form is obtained by orienting the axes so as to eliminate the products of inertia. These new orientations are the principal axes or eigenvectors of the tensor. The lengths of the eigenvectors are the principal moments or eigenvalues of the tensor. Although the great advantage of eigenvalues and eigenvectors is that they are independent of coordinate system (Hayward, 1992; Turvey \& Carello, 1995), intuitions are sometimes easier in the language of moments and products of inertia relative to a particular coordinate system (e.g., with the $z$-axis running longitudinally through a rod). We will
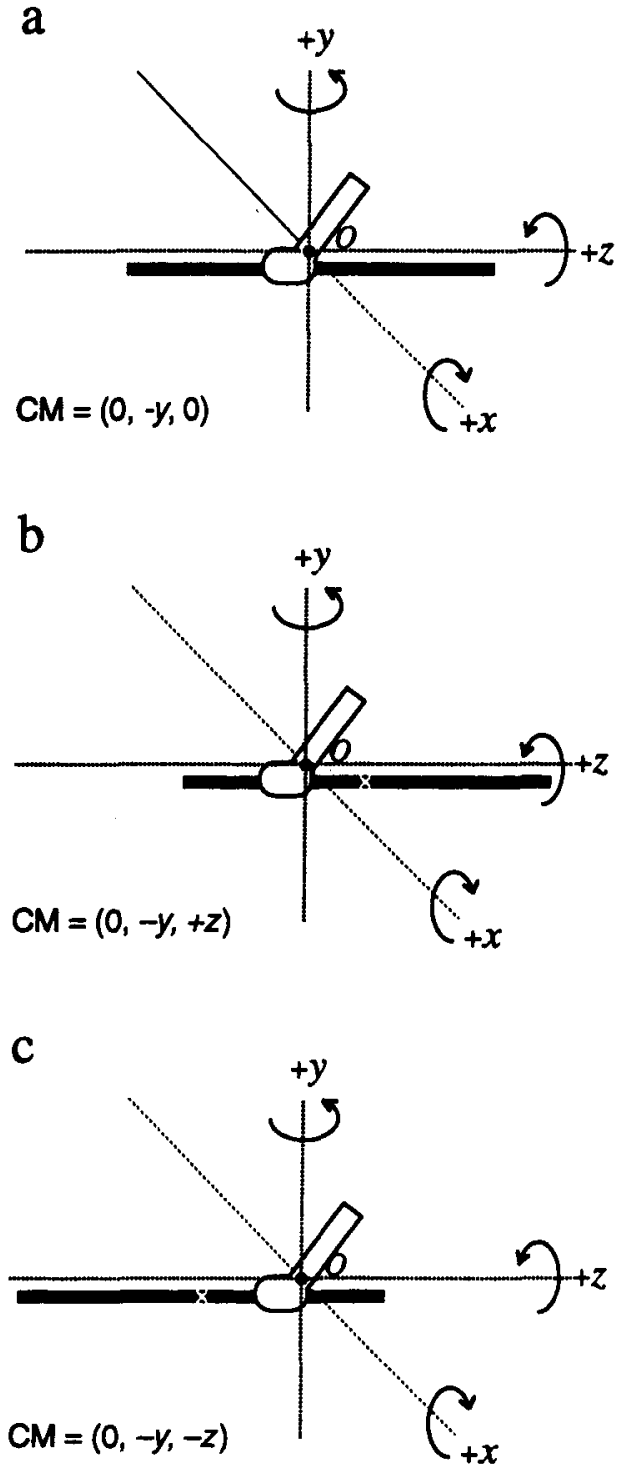

Figure 1. A wielded rod resists rotation about the $x-, y$, and $z$-axes that define a coordinate system centered at a point $O$ in the wrist. In the situations depicted, resistance about $x$ is approximately the same as the resistance about $y$, and both of these are greater than the resistance about $z$. (a) When the rod is held at its center, resistances about $x$ and $y$ are less than when it is held (b) in front of the center of mass $(C M)$ or (c) behind the $C M$. The coordinates of the rod's $C M$ indicate which products are nonzero - in this case, only that product involving the $y$ and $z$ coordinates of (b) and (c), which would themselves differ in sign.

persist in the use of $I_{x x}, I_{y y}, I_{z z}$, and $I_{x y}, I_{y z}$, and $I_{x z}$, therefore, knowing that they can be transformed into principal moments and principal axes by diagonalization.

An extensive body of research now supports the claim that perception by dynamic touch is grounded in $I_{i j}$ (see Turvey \& Carello, 1995, for a review). In particular, it is now understood that perception of an object's magnitudes (e.g., length, width, and mass) is tied primarily to its moments of inertia whereas perception of an object's 
direction (e.g., in space or relative to the body) is tied primarily to its products of inertia. The latter point is of particular interest for present purposes. Investigations of where the object is relative to the hand (requiring subjects to grasp an unseen rod anywhere along its length and then indicate on a visible report rod the proportional position of that grasp) show this directional sensitivity to be a function of $I_{y z}$ (Pagano et al., 1994). $I_{y z}$ effectively tells the perceiver how the rod mass is distributed around the wielding hand. An examination of Equation 4 together with Figure 1 illustrates this point. (We note that objects with different kinds of symmetries may have more than one nonzero product; see, e.g., Pagano \& Turvey, 1992; Turvey, Burton, Pagano, Solomon, \& Runeson, 1992).

Pagano et al. (1994; see also Turvey \& Carello, 1995) speculated that early investigations of perceived partial length, in focusing only on $I_{x x}$, had not fully exploited $I_{i j}$. A tensorial treatment of perceived partial length should obviate the need to decompose any of its components. Given that partial length entails both a magnitude and a direction, this speculation leads to the prediction that the perception of partial length will depend on both moments and products of inertia. But the tensor at issue is that for the whole rod; the moments and products are generated by what is behind the hand as well as what is in front of it. This should allow for an influence of the unattended rod portion on perception of the length of the attended rod portion. How could the original decomposition pattern (i.e., perceived length in front of the hand seemingly unaffected by mass distribution behind the hand; Burton \& Turvey, 1991; Solomon et al., 1989b) have come about? Presumably, the way in which the moments and products relate in determining partial length will sometimes obscure the effect of the unattended portion on perceived length of the attended portion. For a given rod length in front of the hand, for example, very different tensors (i.e., differences in the particular values of the six components) will be produced as a function of whether or not the rear is weighted. But the particular way the components relate in determining perception could negate those differences. To the extent that the quantity formed by the moments and products is the same, perceived partial length should be the same; to the extent that the quantity differs, perceived partial length should differ. Consequently, even under a tensorial analysis, experimental conditions could be such that there would be no statistical effect of the unattended portion of the rod on perceived length of the attended portion. Broadening the range of values of the quantity formed by the moments and products, however, should make that influence apparent.

\section{Is Gravitational Torque a Viable Alternative to $\boldsymbol{I}_{\boldsymbol{i}}$ ?}

In a recent examination of partial length, Chan (1994) questioned the decomposition hypothesis and found a dramatic and consistent effect of the unattended portion of the rod on the attended portion in both holding and wielding. For a fixed partial length, perceived partial length shrank with increases in the inertia of the unattended portion of the rod. In contrast to the foregoing tensorial framework, however, Chan argued that the basis for this influence was the static or gravitational torque $\left(T_{G}\right)$ of the whole rod:

$$
T_{G}=g(m z \cos \phi)
$$

where $g$ is gravitational acceleration, $m$ and $z$ are as in Equations $1-4$, and $\phi$ is the angle of the rod relative to the ground (this formulation is equivalent to Chan's, which used the vector cross-product). When the rod is held still and parallel to the ground, $\phi=0^{\circ}$, its cosine $=$ 1, and Equation 5 reduces to

$$
T_{G}=g m z \text {. }
$$

For a fixed forward length, as the mass behind the hand increases, $T_{G}$ increases. Chan found that this was accompanied by increasingly shorter perceived forward length. $T_{G}$ was said to combine with weight in determining perceived partial length by holding and, through its influence on perceived grip location, to combine with perceived whole length in determining perceived partial length by wielding. In both cases, perceived partial length should decrease with increasing $T_{G}$.

Our suspicion is that the success of $T_{G}$ in Chan's (1994) experiments was parasitic on $I_{i j}$. Notice the similarity between Equations 4 and 6. $T_{G}$ and $I_{y z}$ in this instance simply differ by the constant multiplier of $m z$. But whereas his combination of $T_{G}$ with mass is ad hoc-mass is already reflected in $T_{G}$ but without an additional variable, rods held at the CM (i.e., $T_{G}=0$ ) cannot be distinguished - the combination of moments and products of inertia is principled. Moreover, with respect to wielding, it is not clear how Chan arrived at a single value of $T_{G}$ for each rod combination, given that $\phi$ in Equation 5 changes continuously over time. His calculations indicate that he used Equation 6, inappropriately assuming an unchanging $\phi=0^{\circ}$. The consequence is that what should have been a time-varying $T_{G}$ was perfectly correlated with the time-invariant $I_{y z}$. In other words, Chan's results already implicate $I_{i j}$.

The data themselves, however, are problematic on two fronts. In Chan's (1994) holding experiments, actual partial length never differed; grip was at a fixed distance from the front end of the rod (with either the length or the position of an attached mass behind the hand increasing). Without variation in the requested dimension, participants might be encouraged to use some dimension that did differ. Besides the possibility of demand characteristics, we also note that a fixed grip results in a uniform change in $T_{G}$ with increasing length. Second, unlike previous investigations of perceived length by dynamic touch, participant responses in two experiments grossly underestimated actual lengths. ${ }^{3}$ Such a discrepancy allows the possibility that seemingly incidental methodological features (e.g., participants could see the rule on the report apparatus; some experiments required partici- 
pants to evaluate both partial length and its ratio to whole length) might have produced Chan's pattern of results.

The general goal of the experiments reported here is to show that $I_{i j}$ is the common basis for perceiving partial and whole lengths. Our first two experiments, one with holding and one with wielding, were designed to assess the importance of having only one grip and, therefore, only one actual partial length. Does the basic finding of Chan (1994) replicate when the single grip he used is mixed with two other grips? This manipulation not only addresses the possibility of demand characteristics but also the particular pattern of decreasing perceived forward length as a function of increasing backward length. We expect perceived forward length to change complexly with backward length, in a way that is best captured by $I_{i j}$ rather than $T_{G}$ and mass. To anticipate, the results favor the tensorial hypothesis. The third experiment, therefore, was designed to assess the differing tensorial dependencies of perceived partial length and perceived whole length.

\section{EXPERIMENT 1}

Partial length judgments reported by Chan (1994) revealed an influence of the unattended portions of the rods.
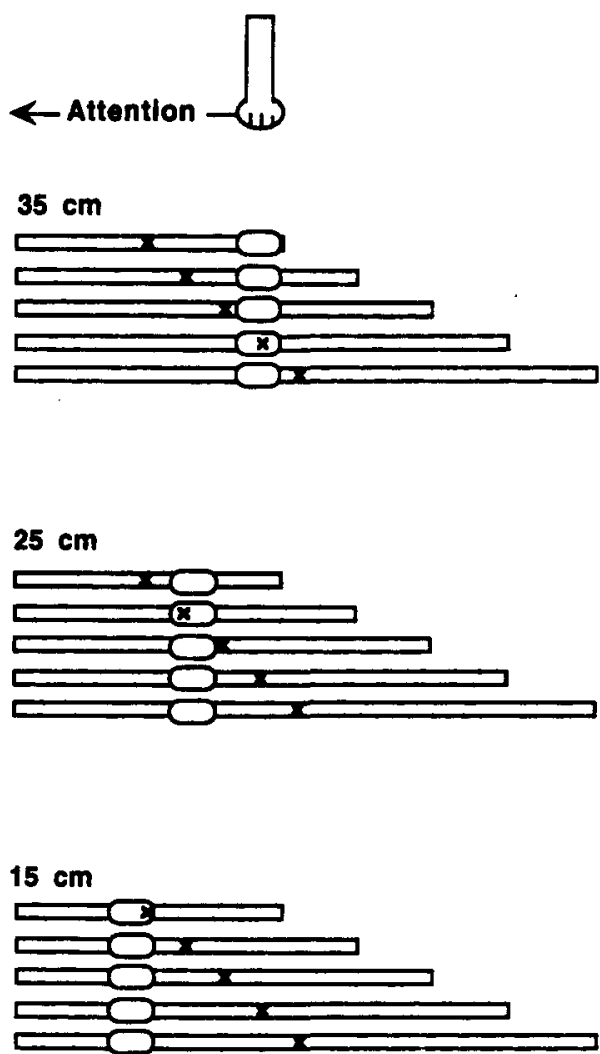

Figure 2. Grip relative to center of mass (marked by $x$ on each rod). Chan's 35-cm grip was used in the fixed conditions and combined with two more grips in the mixed conditions of the present experiments.
Table 1

$I_{i j}$ Components (in $\left.\mathrm{cm} \cdot \mathrm{g}^{2} / 10,000\right)$ as a Function of Grip Distance From the Distal End and Whole Rod Length (in Centimeters) for Experiments 1 and 2

\begin{tabular}{ccrrrrr}
\hline & & \multicolumn{5}{c}{ Rod Length } \\
\cline { 3 - 7 } Grip & Component & \multicolumn{1}{c}{42} & \multicolumn{1}{c}{54} & \multicolumn{1}{c}{66} & \multicolumn{1}{c}{78} & \multicolumn{1}{c}{90} \\
\hline \multirow{4}{*}{15} & $I_{x x}$ & .61 & 1.22 & 2.49 & 4.47 & 7.77 \\
& $I_{y y}$ & .49 & 1.07 & 2.31 & 4.27 & 7.54 \\
& $I_{z z}$ & .12 & .15 & .18 & .20 & .23 \\
& $I_{y z}$ & -.03 & .11 & .31 & .54 & .86 \\
\multirow{3}{*}{25} & $I_{x x}$ & 1.03 & 1.26 & 1.95 & 3.21 & 5.53 \\
& $I_{y y}$ & .92 & 1.12 & 1.77 & 3.01 & 5.30 \\
& $I_{z z}$ & .12 & .15 & .18 & .20 & .23 \\
& $I_{y z}$ & -.23 & -.13 & .01 & .21 & .48 \\
35 & $I_{x x}$ & 2.12 & 2.12 & 2.39 & 3.04 & 4.58 \\
& $I_{y y}$ & 2.00 & 1.97 & 2.21 & 2.85 & 4.35 \\
& $I_{z z}$ & .12 & .15 & .18 & .20 & .23 \\
& $I_{y z}$ & -.42 & -.38 & -.28 & -.12 & .10 \\
\hline
\end{tabular}

Note-The tensor components for the $35-\mathrm{cm}$ fixed-grip condition would be the same as those for the $35-\mathrm{cm}$ grip here. Distance from the rotation point to the rod $(y)$ was $6 \mathrm{~cm}$.

A consideration of $I_{i j}$ as a whole provides an avenue for this influence. The top of Figure 2 shows the $35-\mathrm{cm}$ fixed grip used by Chan relative to the CM for rod lengths approximating his. Note how the grip-CM relationship changes with the shorter grips shown in the lower panels of Figure 2. These changes influence both the size and the sign of the products through the size and sign of $z$ in Equation 4. And because $z$ appears in Equations 1 and 2, $I_{x x}$ and $I_{y y}$ are affected by grip as well. The consequences of different lengths and grips for all components of $I_{i j}$ under the conditions of Experiment 1 are shown in Table 1.

Lengths in the range used in Chan's (1994) first experiment were presented to subjects in either fixed $(35 \mathrm{~cm}$ only) or mixed-grip $(15,25$, and $35 \mathrm{~cm})$ conditions. If the influence of the unattended portion of the rod is replicated only in the fixed-grip condition, Chan's results can be attributed to demand characteristics. If this influence is apparent in the mixed-grip condition as well, then its basis in $T_{G}$ and mass versus $I_{i j}$ can be evaluated. Given the framework that is being proposed here, it is expected that the three grips will produce different patterns of perceived partial length as a function of whole rod length, but that all patterns will be accommodated by a tensorial analysis.

\section{Method}

Subjects. Sixteen students at the University of Connecticut participated in partial fulfillment of a course requirement. Participants were assigned to the fixed- or mixed-grip groups in alternation as they appeared at the laboratory. Six were females; 1 male and 1 female were left-handed.

Materials. Five wooden rods (radius $.64 \mathrm{~cm}$ ) of different lengths and masses $(42 \mathrm{~cm}$ and $34.8 \mathrm{~g}, 54 \mathrm{~cm}$ and $43.2 \mathrm{~g}, 66 \mathrm{~cm}$ and $45.9 \mathrm{~g}$, $78 \mathrm{~cm}$ and $51.7 \mathrm{~g}$, and $90 \mathrm{~cm}$ and $66.4 \mathrm{~g}$ ) were used. Half of the participants always held the rods $35 \mathrm{~cm}$ from the distal end (fixed grip); the remainder held each of the rods at three different hand positions $(15,25$, and $35 \mathrm{~cm}$ from the distal end; mixed grips). At no time before or during the experiment were any of the rods within view. 
Apparatus. A person sat at a student desk with his or her right wrist and forearm supported by the armrest, the right hand extending over the front edge of that support. Styrofoam panels and a curtain occluded the participants' view of anything on their righthand side, including their arm, the rods, and the experimenter. The position of a vertical surface visible in front of the participant was adjusted by means of a joystick to his or her left. This position was recorded by the experimenter from a tape measure to the right of the occluding screen, visible only to the experimenter (see, e.g., Burton \& Turvey, 1991; Figure 3).

Procedure. Once an individual was seated, his or her right arm was placed through the curtain with the wrist at the front edge of the armrest. On each trial, a rod was placed in the participant's hand, parallel to the plane of the floor, and was not released by the experimenter until the person had a firm grip. The participant's task was to estimate the partial length of the rod extending in front of the grasp while holding the rods as still as possible. The participant adjusted the movable surface to coincide with the location of the rod tip (i.e., where the rod would touch the board if that surface extended through the occluding screen). The distance between the participant's wrist and the board was taken as the measurement of the rod's perceived lengths. Before the experimental trials, a rod that was not part of the experimental set was used to demonstrate the mechanics of the experiment to the participants.

Participants were allowed to take as much time as necessary to make each judgment, adjusting the surface back and forth as needed while holding the rod. Once the participants were satisfied with their decision, the experimenter recorded the measurement. After each trial, the experimenter repositioned the board to either 0 (coinciding with the participant's wrist) or $2.3 \mathrm{~m}$, thereby precluding
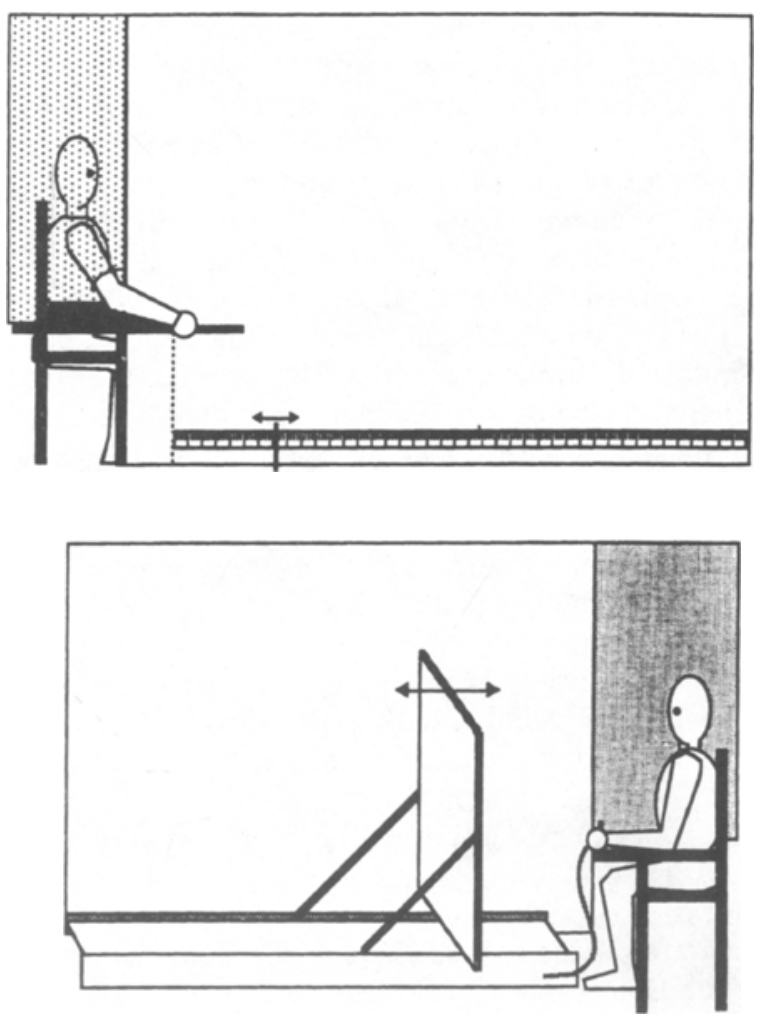

Figure 3. Top: view on the experimenter's side of the occlusion screen. A participant held the rod out of view with the designated grip. The forearm was supported by an armrest. Bottom: view on the participant's side of the occlusion screen. The position of a vertical surface was adjusted by means of a joystick.
Table 2

Perceived Length (in Centimeters) as a Function of Grip Distance From the Distal End and Whole Rod Length (in Centimeters) for Fixed and Mixed Grips Under Conditions of Holding (Experiment 1)

\begin{tabular}{cccccc}
\hline & \multicolumn{5}{c}{ Rod Length } \\
\cline { 2 - 5 } Grip Distance & 42 & 54 & 66 & 78 & 90 \\
\hline \multicolumn{5}{c}{ Fixed Grip } \\
35 & 39.61 & 36.49 & 31.04 & 27.15 & 23.35 \\
\multicolumn{5}{c}{ Mixed Grips } \\
15 & 26.87 & 29.13 & 33.04 & 39.43 & 40.02 \\
35 & 31.26 & 31.76 & 31.93 & 33.20 & 35.11 \\
35 & 46.16 & 50.08 & 38.23 & 37.01 & 38.62 \\
\hline
\end{tabular}

Note-Perceived lengths include the width of the hand whereas grip distance is measured from the distal tip of the rod to the front of the hand. Therefore, actual partial length for each grip position is obtained by adding the width of the hand $(\approx 7 \mathrm{~cm})$ to each grip distance.

a comparison of successive responses. For the fixed-grip group, there were nine observations of each rod length, presented in random order, for a total of 45 trials. For the mixed-grip group, there were three observations of each length at each grip, randomized within replication blocks, also for a total of 45 trials.

\section{Results and Discussion}

Mean perceived lengths as a function of length and grip position are provided in Table 2 and indicate that perceived lengths are in approximately the range of the actual lengths that were used. In particular, actual partial lengths ranging from 22 to $42 \mathrm{~cm}$ (measuring from the rotation point in the wrist) were perceived in a range from 27 to $50 \mathrm{~cm}$. For the fixed-grip group, a one-way analysis of variance (ANOVA) revealed length to be significant $[F(4,28)=8.03, p<.0002]$. Consistent with Chan (1994), perceived length of a fixed-rod segment was a decreasing function of overall rod length (the slope of the simple regression of perceived partial length on whole rod length was -.35 ). For the mixed-grip group, a 3 (grip) $\times 5$ (length) ANOVA revealed no significant main effects for grip $[F(2,14)=3.01, p>.08]$ or length $(F<1)$. Their influence was apparent in the interaction, however $[F(8,56)=2.57, p<.02]$. As can be seen from Table 2, with mixed grips, perceived length of a partial rod segment was again a decreasing function of overall length for the $35-\mathrm{cm}$ grip, although not as cleanly as in the fixed-grip condition (the slope of the simple regression of perceived partial length on whole rod length was -.24 , but not significant; $p>.10$ ). However, cont rary to expectations from Chan's (1994) general arguments, perceived length does not routinely decrease with increasing length of the rear portion of the rod. It increased with overall length for the $15-\mathrm{cm}$ grip (the slope of the simple regression of perceived partial length on whole rod length was $+.31 ; p<.005)$ and changed much more gradually for the $25-\mathrm{cm}$ grip (the slope of the simple regression of perceived partial length on whole rod length was $+.08 ; p<.02$ ).

Focusing on the $35-\mathrm{cm}$ grip, although the means for the two conditions differed (fixed grip $=31.53$, mixed 
grip $=42.02 ; p<.005$ ), the pattern of results was basically the same. The decrease in perceived forward length with increasing backward length does not seem to derive from demand characteristics or methodological considerations. Consistent with Chan (1994), the regression of perceived length on $T_{G}$ of the whole rod for the fixedgrip condition was significant and substantial $\left(r^{2}=.93\right.$, $p<.01$ ). Keeping in mind that $T_{G}$ is proportional to $I_{y z}$, however, this same $r^{2}$ characterizes the regression on $I_{y z}$ (with only 5 data points, consideration of additional regressors for either hypothesis is precluded).

When three grips were mixed, the overall reliance on $T_{G}$ was not significant $\left(r^{2}=.03\right.$; Figure $\left.4 \mathrm{a}\right)$, nor was a multiple regression including rod mass with $T_{G}\left(r^{2}=.18\right.$, $p>.30)$. However, the principled combination of $I_{y z}$ and the other tensor components was successful. A multiple regression of $\log$-perceived rod segment onto the components of $I_{i j}$ revealed significant contributions of $\log$ $I_{x x}, \log I_{z z}$, and $\log \left(1+I_{y z}\right)\left(r^{2}=.80, p=.0004\right.$, with coefficients of $.48,-.84$, and .06 , respectively).$^{4}$ The fit to the power equation is shown in Figure $4 \mathrm{~b}$. This regres-

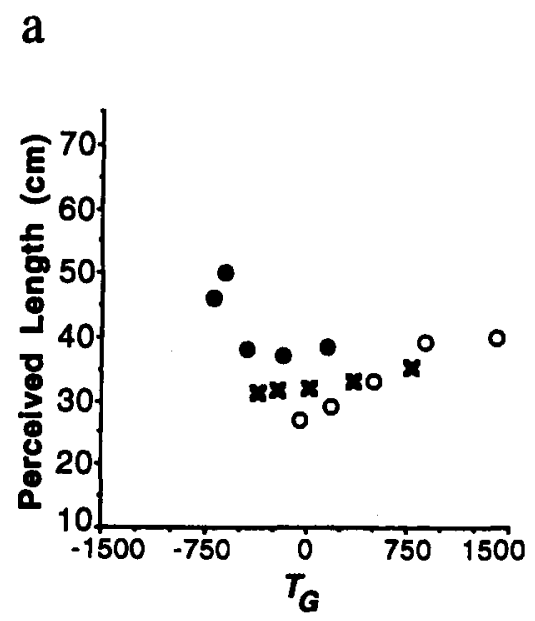

b

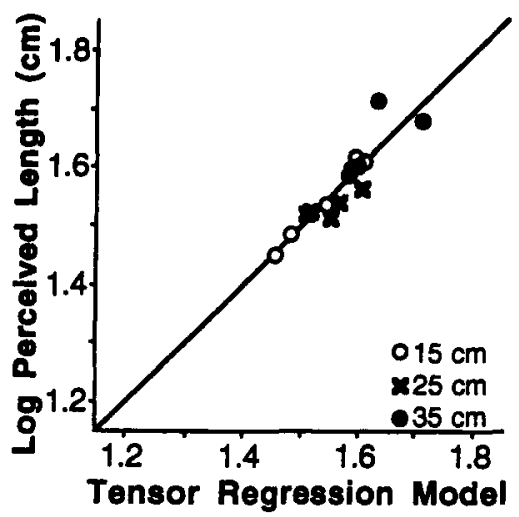

Figure 4. Mixed-grip condition for holding in Experiment 1. (a) Perceived length as a function of gravitational torque, $T_{G}$; (b) $\log$ perceived length as a function of the tensor regression model. sion was significant for 7 of 8 individual subjects. Moreover, consistent with the findings of Fitzpatrick et al. (1994) and Turvey, Burton, Amazeen, Butwill, and Carello (1995), the contributions of both $I_{x x}$ and $I_{z z}$ were significant and opposite in sign.

The tensor provides a general account of perceived partial length by holding to accommodate influences brought about by a variety of grip and length combinations. But, consonant with previous findings on perception of partial length (Burton \& Turvey, 1990, 1991; Solomon \& Turvey, 1988; Solomon et al., 1989b), we note that there was a circumscribed set of objects for which perceived partial length was essentially unaffected by the unattended portion of the rod. When the grip was at $25 \mathrm{~cm}$, post hoc $t$ tests indicated no differences between any pairs of rod lengths $(p>.05)$. At that grip, perceived partial length was within $3 \mathrm{~cm}$ of actual partial length, indifferent to whole rod lengths (which differed by $50 \mathrm{~cm}$ ). But as Figure $4 \mathrm{~b}$ shows, this perceived partial length pattern is to be expected from the relationship among components of $I_{i j}$. And it is the relation among these components that rationalizes the success of partial static moment in the early decomposition experiments: Static moment of the rod portion in front of the hand is largely constrained by the tensor components $\left(r^{2}=.98\right.$; see also Pagano, Carello, \& Turvey, 1996, who made this same observation for the rotational inertia of the partial rod). Importantly, the same tenso- relationships underlie circumstances in which the unattended portion of the rod affects perceived length of the attended rod portion.

We should address the significance of rotational components in a task where instructions emphasized that participants hold the rods without moving them. Had they been completely successful in following these instructions, the rotational components should not have been available. However, seemingly incidental sway or tremor might be sufficient to render these invariants of rotational dynamics accessible. Riccio (1993) has argued that tremor is not innocuous noise; rather, it is an important source of exploratory behavior (e.g., in facilitating perception of the region of postural stability). And far from being random, tremor reflects the fundamental rhythmic synergies of the body. For example, the involuntary fluctuations that occur during an effort to maintain a constant posture of the finger reflect periodicities due to respiration, cardiac pulse, and extensor muscle activity (Padsha \& Stein, 1973). Our own measures of the fluctuations that accompany holding the rods of Experiment 1 reveal a pattern with reliable structure: The periodicity due to cardiac pulse is apparent for every rod (see the Appendix). Considering the additional activity of our participants' moving the left hand to operate the report apparatus as the rod was held in the right hand, the accessibility of rotational components even under an instruction to hold a rod without moving it is not surprising. Although such movements are subtie, we note that similarly subtle head movements are critical to perceiving whether a given surface can be sat upon. In particular, when the head movements that ordinarily accompany 
standing still are precluded simply by having the observer lean back with the head pressed against a wall, perceptual accuracy in evaluating a surface's suitability for sitting is greatly reduced (Mark, Balliett, Craver, Douglas, \& Fox, 1990).

The relevance of $I_{i j}$ for perceiving partial length has been shown with minimal movement. Nonetheless, holding and wielding are distinct tasks even though their distinctiveness does not require that the intention to hold a rod still can be carried out perfectly. The consequences of restricted exploration are reflected in the relatively modest $r^{2}$, which is usually closer to .90 for length perception by dynamic touch. If the tensorial account of perceiving partial length is correct, an assessment with free wielding should reveal it even more strongly. This was the focus of Experiment 2.

\section{EXPERIMENT 2}

Chan (1994) argued that since moment of inertia does not embody direction, during wielding it must be augmented with $T_{G}$ in order to account for perceived grip ratio and thereby partial length by wielding. There are three counters to this argument. First, whereas $I_{x x}$ does not embody direction, $I_{i j}$ does in the quantification of the asymmetry of the mass distribution captured in the offdiagonal terms (as entailed in the eigenvectors when the products are eliminated through diagonalization). Second, and relatedly, it has already been noted that perceived grip is tensor based (Pagano et al., 1994). Third, contrary to Chan's implication, continuous changes in $\phi$ mean that $T_{G}$ is not constant when a rod is wielded. Even if we allow that $\phi=0^{\circ}$ may have been an appropriate average in Chan's experiment, where wielding was restricted to movement at the wrist in the $y-z$ plane (although, given the range of motion possible at the wrist, this is dubious), releasing some restrictions on wielding will preclude this concession. In Experiment 2, the conditions of Experiment 1 were repeated with the exception that participants were permitted to wield the rods with only the position of the elbow fixed; they were otherwise free to use the entire forearm and wield in any plane.

Under these conditions, the calculation of $T_{G}$ would have to include time series at both joints, modeled after the following time slice for a rod held at the end (Saltzman, 1979):

$$
\begin{aligned}
T_{G \text { elbow }}= & -g\left(L_{\mathrm{e}} \cos \phi_{\mathrm{e}}\left(1 / 2 m_{\mathrm{e}}+m_{\mathrm{w}}\right)\right. \\
& \left.+1 / 2 m_{\mathrm{w}} L_{\mathrm{w}} \cos \left(\phi_{\mathrm{e}}+\phi_{\mathrm{w}}\right)\right), \\
T_{G \text { wrist }}= & -g\left(1 / 2 m_{\mathrm{w}} L_{\mathrm{w}} \cos \left(\phi_{\mathrm{e}}+\phi_{\mathrm{w}}\right)\right),
\end{aligned}
$$

where $L_{\mathrm{e}}$ is the length of the forearm, $L_{\mathrm{w}}$ is the length of the rod, $\phi_{\mathrm{e}}$ is the angle of the forearm to the ground plane, and $\phi_{\mathrm{e}}+\phi_{\mathrm{w}}$ is the angle of the rod to the ground plane. Patently, gravitational torque is not an invariant of wielding and it cannot be treated as such in approximation. Perceived partial length by wielding is expected to be a function of the invariant $I_{i j}$ (defined at the wrist; see note 2) that couples the variant torques and motions (Turvey \& Carello, 1995).

\section{Method}

Subjects. Sixteen students at the University of Connecticut participated in partial fulfillment of a course requirement. They were assigned to the fixed-or mixed-grip groups in alternation as they appeared at the laboratory. Two were males; 3 of the females were left-handed.

Apparatus and Materials. The response apparatus and rods were the same as those in Experiment 1.

Procedure. Once the rod was placed into the subject's hand, he or she was allowed to wield it in order to determine its length. The subject still had to grip the rod firmly; movements from the elbow were otherwise unrestricted. Movement in any direction was permitted as long as the rod did not hit the surrounding surfaces. So that adjustments of the visible surface were comparable to those from Experiment 1, the wrist was returned to the edge of the arm support before the response was made. In all other respects, the procedure was the same as that in Experiment 1.

\section{Results and Discussion}

Mean perceived lengths as a function of length and grip position are provided in Table 3 and indicate that perceived lengths are in approximately the range of the actual lengths that were used. In particular, actual partial lengths ranging from 22 to $42 \mathrm{~cm}$ (measuring from the rotation point in the wrist) were perceived in a range from 14 to $33 \mathrm{~cm}$. For the fixed-grip group, a one-way ANOVA revealed length to be significant $[F(4,28)=5.31, p<.003]$. Consistent with Chan (1994, Experiment 3), perceived length of a fixed-rod segment was a decreasing function of overall rod length when the rod was wielded (the slope of the simple regression of perceived partial length on whole rod length was -.12). For the mixed-grip group, a 3 (grip) $\times 5$ (length) ANOVA revealed a significant effect of grip $[F(2,14)=17.83, p<$ $.0001]$, with mean perceived lengths of $18.47,21.3$, and $28.1 \mathrm{~cm}$ for the $15-, 25-$, and $35-\mathrm{cm}$ grips, respectively. Although the effect of length was not significant $(F<1)$, its influence was again apparent in the interaction $[F(8,56)=$ $4.32, p<.0004]$. As can be seen from Table 3 for mixed grips, perceived length of a partial rod segment was again a decreasing function of overall length for the $35-\mathrm{cm}$ grip (the

Table 3

Perceived Length (in Centimeters) as a Function of Grip Distance From the Distal End and Whole Rod Length (in Centimeters) for Fixed and Mixed Grips Under Conditions of Wielding (Experiment 2)

\begin{tabular}{cccccc}
\hline & \multicolumn{5}{c}{ Rod Length } \\
\cline { 2 - 6 } Grip Distance & 42 & 54 & 66 & 78 & 90 \\
\hline \multirow{5}{*}{35} & 32.95 & 32.57 & 29.27 & 29.11 & 27.49 \\
\multicolumn{5}{c}{ Mixed Grips } \\
15 & 14.06 & 17.00 & 19.76 & 20.91 & 20.62 \\
25 & 20.44 & 19.48 & 20.41 & 21.23 & 24.86 \\
35 & 30.78 & 28.44 & 28.13 & 26.70 & 26.51 \\
\hline
\end{tabular}

Note-Perceived lengths include the width of the hand whereas grip distance is measured from the distal tip of the rod to the front of the hand. Therefore, actual partial length for each grip position is obtained by adding the width of the hand $(\approx 7 \mathrm{~cm})$ to each grip distance. 
slope of the simple regression of perceived partial length on whole rod length was $-.11 ; p<.005$ ). But once again, contrary to Chan (1994), perceived length increased with overall length for the $15-\mathrm{cm}$ grip (the slope of the simple regression of perceived partial length on whole rod length was $+.14 ; p<.025$ ) and did not change for the $25-\mathrm{cm}$ grip (the slope of the simple regression of perceived partial length on whole rod length was $+.09 ; p>.10$ ).

As noted, $T_{G}$ cannot be evaluated straightforwardly during wielding. To the time derivative requirement already mentioned, we add that participants differed in the extent to which they used motions at the elbow, and this differed as a function of rod length. This means that Chan's (1994) implicit assumption that $\phi=0^{\circ}$ for all conditions and all participants cannot even be entertained here. For the fixed-grip condition, the regression of perceived length on $I_{y z}$ was significant $\left(r^{2}=.84, p=\right.$ .03 ; again, the small $d f$ preclude more regressors). When the three grips were mixed, a multiple regression of $\log$ perceived rod segment onto the components of $I_{i j}$ again revealed significant contributions of $\log I_{x x}, \log I_{z z}$, and $\log \left(1+I_{y z}\right)\left(r^{2}=.92, p=.0001\right.$, with coefficients of .55 , -.68 , and .15 , respectively). The fit to the power equation is shown in Figure 5. This regression was significant for all individual subjects. Again, consistent with previous findings, the exponents on $I_{x x}$ and $I_{z z}$ were opposite in sign (Fitzpatrick et al., 1994; Turvey et al., 1995).

Under conditions of free wielding, the tensor components were revealed unambiguously to be responsible for variation in perceived partial length. $T_{G}$ is not an invariant of wielding; it cannot be calculated as Chan (1994) did. Its actual calculation would seem to require a piecewise linearization for each participant on line as a function of his or her particular pattern of wielding (see Saltzman, 1979, for the requisite computations of muscular and gravitational torques for movements performed in a gravitational field).

\section{DISCUSSION OF EXPERIMENTS 1-2}

We began with the question of whether the data reported by Chan (1994) showed a reliable influence of the

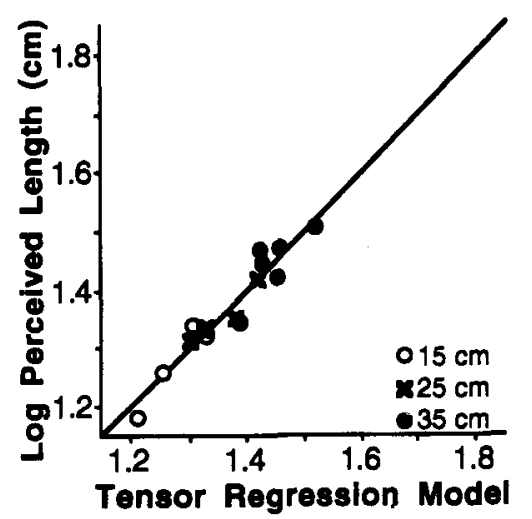

Figure 5. Mixed-grip condition for wielding in Experiment 2. unattended portion of a rod on the perception of the length of the attended portion. The question arose because Chan did not alter actual partial length in his two holding experiments, used only two actual lengths in his wielding experiment, and reported perceptual responses that were gross underestimates in two of his experiments. The present Experiment 1 showed a difference in means for the $35-\mathrm{cm}$ grip in the fixed and mixed conditions in holding (Table 2), which may indicate that the lack of variation is difficult to scale when exploration is severely restricted. Nonetheless, the first two experiments of the present series show that the influence of the unattended rod portion is not restricted to the fixed-grip condition. Moreover, this influence remains when, as in the present experiments, perceived lengths are in the appropriate range for actual lengths. Of importance, however, is the demonstration that the usefulness of $T_{G}$ is limited and superseded by a consideration of all tensorial components (see Pagano et al., 1994; Turvey \& Carello, 1995). Indeed, since the assumption of a fixed angle during wielding guarantees that the proxy for $T_{G}$ is perfectly correlated with $I_{y z}$, any explanatory power accorded $T_{G}$ in Chan's Experiment 3 derived from $I_{y z}$. The tensorial account also has the advantage of rationalizing the pattern of results that originally led to the decomposition hypothesis.

The tensorial hypothesis that has been under investigation was motivated by the developing approach to dynamic touch that highlights the relationship of $I_{i j}$ to an object's magnitudes and directions. Given that partial length is a magnitude in a direction, it was expected to be a function of both moments and products of inertia. This hypothesis has been supported in two experiments. The remaining question is whether, under identical circumstances, perceived whole length and perceived partial length will reveal different tensorial dependencies. This was the focus of Experiment 3.

\section{EXPERIMENT 3}

Perceived whole length has been found to be a function of moments of inertia in many experiments. Of the more recent investigations of the whole tensor (Fitzpatrick et al., 1994; Pagano et al., 1993; Pagano \& Turvey, 1993), all have been limited to a grip location at the end of the rod. Consequently, the absence of an influence of an offdiagonal component may simply be a lack of variation in that component (e.g., the sign of the product did not change). The tensorial account of selective perception by dynamic touch, however, suggests that even with variation in $I_{y z}$-variation that will affect perceived partial length - perceived whole length should remain a function only of moments of inertia. The number of actual partial lengths was increased relative to those of the first two experiments. Three rod lengths were grasped at $1 / 4$, $1 / 2$, or $3 / 4$ of their total lengths, resulting in nine partial lengths with nine different tensors (Table 4). Since $I_{x x}$, $I_{y y}$, and $I_{z z}$ for the $1 / 4$ grip are the same as those for the $3 / 4$ grip, however, these two conditions for each rod should 
result in the same perceived whole length. That is, the nine tensors will produce only six different perceived whole lengths.

\section{Method}

Subjects. Eight students at the University of Connecticut participated in Experiment 3 in partial fulfillment of a course requirement. None of the subjects had participated in the previous experiments. Six of the subjects were males (one of whom was left handed).

Materials. Three wooden rods (radius $.64 \mathrm{~cm}$ ) of different lengths and masses (42 cm and $34.4 \mathrm{~g}, 66 \mathrm{~cm}$ and $45.1 \mathrm{~g}$, and $90 \mathrm{~cm}$ and $64.8 \mathrm{~g}$ ) were used. A rod that was not part of the experimental set was used to demonstrate the mechanics of the experiment.

Apparatus. The apparatus was the same as in Experiments 1 and 2.

Procedure. The same procedure as in the two previous experiments was followed with a few exceptions. The participants' task in Experiment 3 was, depending on the trial, to estimate either the partial or the whole length of the rods. The grips were $1 / 4,1 / 2$, and $3 / 4$ of a given rod's length, producing nine different partial lengths (rods were placed in a participant's hand so that, for example, the $1 / 4$ mark on the rod was centered in the hand). At the beginning of each trial, the experimenter instructed the subjects whether they were to estimate the forward segment of the rod (partial length) or the entire extent of the rod (whole length). With respect to whole length, the instructions emphasized that length was to be reported as if the rod were held at one end. Participants could freely wield the rod, just as in Experiment 2.

Design. The combination of three hand positions, three rod lengths, and two different reports (partial vs. whole length) yielded a total of 18 conditions that were ordered randomly. Each condition was presented three times, yielding a total of 54 trials per subject. Each set of 18 was completed before any condition was repeated.

\section{Results and Discussion}

Mean perceived lengths as a function of whole rod length, grip position, and attention to partial or whole rod length are provided in Table 5 and indicate that perceived lengths are in the appropriate range for the actual lengths that were used. In particular, actual partial lengths from 14 to $71 \mathrm{~cm}$ were perceived as 20 to $63 \mathrm{~cm}$; actual whole lengths from 42 to $90 \mathrm{~cm}$ were perceived as 35 to $80 \mathrm{~cm}$. A $3 \times 3 \times 2$ (length $\times$ grip $\times$ attention) ANOVA revealed that all main effects and interactions were significant. Whole perceived length $(58.11 \mathrm{~cm})$ was reliably

Table 4

$I_{i j}$ Components (in $\mathrm{cm} \cdot \mathrm{g}^{2 / 10,000)}$ as a Function of Grip and Whole Rod Length (in Centimeters) for Experiment 3

\begin{tabular}{ccccc}
\hline & & \multicolumn{3}{c}{ Rod Length } \\
\cline { 3 - 5 } Grip & Component & 42 & 66 & \multicolumn{1}{c}{90} \\
\hline \multirow{4}{*}{$1 / 4$} & $I_{x x}$ & 1.01 & 3.03 & 7.89 \\
& $I_{y y}$ & .89 & 2.87 & 7.66 \\
& $I_{z z}$ & .12 & .16 & .23 \\
& $I_{y z}$ & .22 & .45 & .87 \\
$1 / 2$ & $I_{x x}$ & .63 & 1.80 & 4.61 \\
& $I_{y y}$ & .51 & 1.64 & 4.37 \\
& $I_{z z}$ & .12 & .16 & .23 \\
& $I_{y z}$ & .00 & .00 & .00 \\
$3 / 4$ & $I_{x x}$ & 1.01 & 3.03 & 7.89 \\
& $I_{y y}$ & .89 & 2.87 & 7.66 \\
& $I_{z z}$ & .12 & .16 & .23 \\
& $I_{y z}$ & -.22 & -.45 & -.87 \\
\hline
\end{tabular}

Table 5

Perceived Length as a Function of Whole Rod Length, Proportional Grip Location, and Attention to Partial or Whole Length in Experiment 3

\begin{tabular}{llcr}
\hline & \multicolumn{3}{c}{ Rod Length } \\
\cline { 2 - 3 } Grip Location & 42 & 66 & 90 \\
\hline \multirow{4}{*}{ Partial Length } \\
$1 / 4 \mathrm{~L}$ & 20.03 & 29.40 & 32.35 \\
$1 / 2 \mathrm{~L}$ & 21.88 & 31.84 & 43.40 \\
$3 / 4 \mathrm{~L}$ & 28.08 & 44.96 & 62.46 \\
& Whole Length & & \\
$1 / 4 \mathrm{~L}$ & 40.40 & 60.89 & 79.46 \\
$1 / 2 \mathrm{~L}$ & 34.75 & 51.45 & 73.28 \\
$3 / 4 \mathrm{~L}$ & 41.57 & 62.64 & 78.52 \\
\hline
\end{tabular}

Note-All measurements are in centimeters.

longer than partial perceived length $(34.93 \mathrm{~cm})[F(1,7)=$ $247.76, p<.0001]$; perceived length increased with an increase in actual length $[F(2,14)=116.30, p<.0001]$ $(42-, 66-$, and $90-\mathrm{cm}$ rods averaged $31.12,46.86$, and $61.58 \mathrm{~cm}$, respectively); and grip location influenced perceived length $[F(2,14)=42.05, p<.0001](1 / 4 \mathrm{~L}, 1 / 2$ $\mathrm{L}$, and $3 / 4 \mathrm{~L}$ averaged $43.75,42.78$, and $53.04 \mathrm{~cm}$, respectively). The significant interactions [length $\times$ grip, $F(4,28)=7.09, p<.0004$; length $\times$ attention, $F(2,14)=$ $45.35, p<.0001$; grip $\times$ attention, $F(2,14)=36.86, p<$ .0001 ; and length $\times$ grip $\times$ attention, $F(4,28)=11.98$, $p<.0001]$ highlight the importance of the mass distribution and its different role in perceiving partial and whole length. This is best illustrated by the grip $\times$ attention interaction (Figure 6). As predicted, when attention is directed to perceiving the length of the whole rod, the $1 / 4$ and $3 / 4$ grips do not differ from each other and both are larger than the $1 / 2$ grip (replicating Solomon, Turvey, \& Burton, 1989a, in which wielding was restricted to the wrist joint). In contrast, when attention is directed to perceiving the length of the rod in front of the hand, the $3 / 4$ grip is larger than the $1 / 2$ grip, which is larger the $1 / 4$ grip. Post hoc $t$ tests (with $p=.05$ ) verified these predictions for each rod length.

Of particular importance for present purposes, this difference between partial and whole length perception was apparent in the regressions on components of $I_{i j}$. As has been found previously for homogeneous rods, perception of whole length was completely determined by $I_{x x}\left(r^{2}=.99, p<.0001\right)$ in $\log -\log$ coordinates (Figure $7 \mathrm{a})$; the contribution of $\log \left(1+I_{y z}\right)$ was not significant in a multiple regression (partial $F<1, p>.90$ ). Close inspection of the figure reveals three pairs of overlapping open circles corresponding to the $1 / 4$ and $3 / 4$ grips for the three rod lengths. Their equal $I_{x x}$ gave rise to equivalent perceived lengths (Solomon et al., 1989a). In contrast, the multiple regression of log partial length on $\log I_{x x}$ and $\log \left(1+I_{y z}\right)$ revealed both components to be significant (partial $F \mathbf{s}=98.48, p<.0001$, and 52.15, $p<$ .0004 , respectively), with an overall $r^{2}=.96(p=.0001)$. For comparison with whole length, the simple regression of log partial length on $\log I_{x x}$ is overlaid on the regression for whole length (Figure 7a). The exponent was ap- 


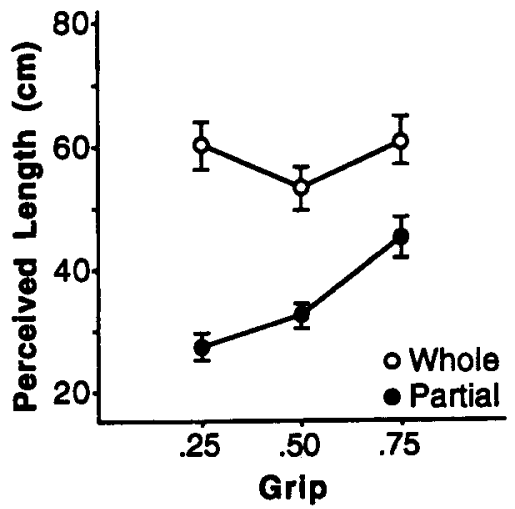

Figure 6. Perceived whole length for the $1 / 4$ and $3 / 4$ grips in Experiment 3 does not differ whereas perceived partial length does.

proximately the same $(.31)$ but the fit was not as tight $\left(r^{2}=.63\right)$. Here, the pairs that were equal with respect to $I_{x x}$ were not equivalent with respect to perceived partial length. This additional variance is the contribution of the product of inertia. Figure $7 \mathrm{~b}$ shows a significant regression of this residual variance onto $I_{y z}$ (together with a nonsignificant regression of the residual from perceived whole length). Unlike Experiments 1 and $2, I_{z z}$ was not significant. This is due to the use of only three rod lengths, which resulted in only three values of $I_{z z}$ rather than the five values produced by the five lengths of Experiments 1 and 2.

Importantly, these regressions of perceived length on the components of $I_{i j}$ reflect the degree to which $I_{i j}$ predicts actual length. A regression of actual whole length on $I_{i j}$ reveals only $I_{x x}$ to be significant, with an $r^{2}=.92$ and an exponent (in $\log -\log$ coordinates) of .35; a regression of actual partial length on $I_{i j}$ reveals both components to be significant, with an $r^{2}=.75$ and exponents of .40 on $\log I_{x x}$ and .47 on $\log 1+I_{y z}$. The significance of these last observations is that perceived length reflects closely the tensorial relationships that underlie actual length.

Chan's (1994) analysis of his Experiment 3 showed a high correlation of perceived partial length with perceived whole length and perceived length ratio (see his Figure 8), implying that the percepts were coupled. Although not labeled as such by Chan, this account is reminiscent of percept-percept coupling (Epstein, 1982). Epstein (1977) has argued that proof of such a coupling requires a statistical evaluation by means of partial correlation. Namely, the relationship between percepts should remain when a physical variable is partialed out, whereas the relationship between the "focal" percept and the physical variable should diminish when the "mediating" percept is removed. This evaluation was conducted for Experiment 3 of the present series (for further discussion of this point in dynamic touch, see Barac-Cikoja \& Turvey, 1995; Carello, Fitzpatrick, \& Turvey, 1992; Chan \& Turvey, 1991). The correlation between perceived partial length and perceived whole length is .77 , but when the relationship to $I_{x x}$ and $I_{y z}$ is removed, this drops to a non- significant .24 . In contrast, the relationship between perceived partial length and the components of $I_{i j}$ remains significant $(r=.82, p<.01)$ when perceived whole length is removed.

The tensorial analysis of Experiment 3 showed a distinction between perceived partial length and perceived whole length under circumstances in which the unattended portion of the rod was found to make a statistical difference to perceived length of the attended portion. But we argued in the Introduction that the analysis should hold even when conditions are such that the unattended portion does not prove significant in the analysis of variance. Consequently, the data for the two experiments of Solomon et al. (1989b) were reanalyzed to evaluate the whole tensor. Consistent with the foregoing, regression analyses revealed log perceived whole length to be a function of $\log I_{x x}$ alone $\left(r^{2}=.85, p=.0001\right)$, whereas $\log$ perceived partial length was a function of both $\log I_{x x}$ and $\log \left(1+I_{y z}\right)\left(r^{2}=.88, p=.0001\right)$. Even when the unattended rod portion has no discernible effect on perception of the attended portion, perceived partial length is a law-governed function of $I_{i j}$.

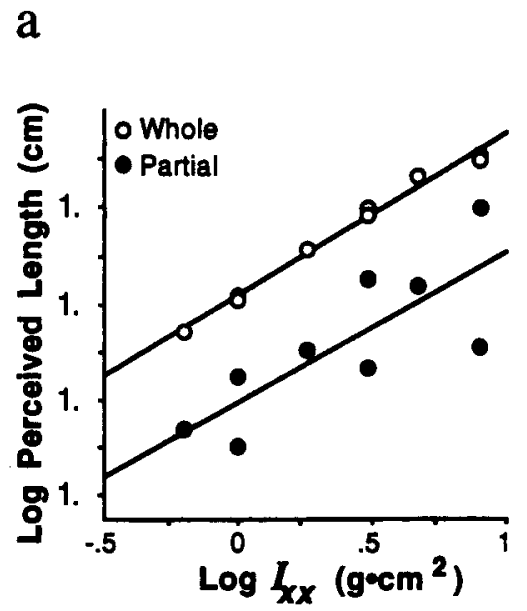

b

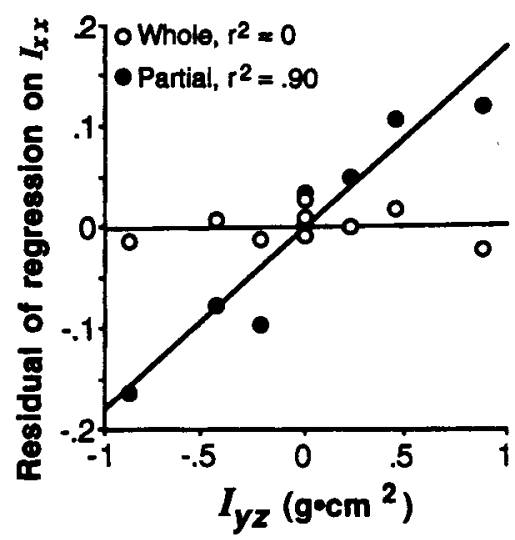

Figure 7. (a) Regressions of $\log$ perceived length as a function of $\log$ $I_{x x}$ for whole and partial length estimations. (b) Regression onto $I_{y z}$ of the residuals of the regressions shown in (a). 


\section{GENERAL DISCUSSION}

A developing account of perception by dynamic touch asserts that $I_{i j}$ underlies the perception of persistent properties of objects such as their magnitudes and directions (both relative to the environment and relative to the perceiver). In particular, properties having to do with magnitudes (e.g., length, Fitzpatrick et al., 1994; heaviness, Amazeen \& Turvey, 1996; shape, Burton, Turvey, \& Solomon, 1990; Turvey et al., 1995) map onto the principal moments of $I_{i j}$, whereas properties having to do with direction (e.g., object orientation, Pagano \& Turvey, 1992; grip location, Pagano et al., 1994; limb orientation, Pagano \& Turvey, 1995) map onto principal directions or eigenvectors of $I_{i j}$.

Although it has been well established that whole length and partial length can be perceived by dynamic touch, the original decomposition hypothesis did not exploit rotational dynamics fully. The present experiments, in recognizing that partial length is a magnitude in a direction, have revealed the tensorial basis to this instance of selective haptic perception. In particular, these experiments highlight the importance of both diagonal and off-diagonal components. Although this account is very different from splitting a single component into two parts, the scaling of magnitudes on the basis of relationships wholly within the tensor is a reasonable facsimile of the functional decomposition conjectured in earlier investigations. In addition, Experiment 3 showed that the very same tensor can be used by the haptic perceptual system in different ways to satisfy two different intentions: perceive part or all of a rod's length.

\section{Specificity of Information and Perception}

This last point is, in fact, similar to Chan's (1994) argument that functions map a limited number of variables into a large number of perceptions. One crucial difference, however, is the kinds of variables considered relevant. Our experiments add to a growing series that shows that the wide variety of properties that can be perceived by dynamic touch are constrained wholly by the timeinvariant $I_{i j}$. Chan's limited consideration of a single moment of inertia forced him outside the tensor and into relying on time-varying quantities such as static torque, inertial torque, angular acceleration, and the ratio of downward to upward forces at the front and back edges of the hand. In particular, he was led to a conclusion of multiple specification. But the time-varying quantities are guaranteed to be limited in applicability, their usefulness determined by the extent to which they happen to coincide with $I_{i j}$. A similar limitation applies to his conclusion that "perceived forward length is found to be specified by static torque and also by perceived whole length divided by perceived length ratio" (p. 560). All of these perceived properties are tensor based and so they will, at some level, be related. But, as we showed in the analysis of Experiment 3 , they are not related in the sense of one percept being used to derive another percept.
The results of this research point once again to specificity in dynamic touch. Following from Gibson's (1959, $1966,1979)$ theory of perception, we characterize the specificity of information in two logical directions. First, information is specific to the environment and to one's movements. Second, perception is specific to information. Together, these mean that perception is specific to the environment and one's movements. The emphasis of the mapping entailed by information-environment specificity is on the lawfulness of the relationship between environmental properties and the energy distributions structured by them that are available to a perceptual system. The emphasis of the mapping entailed by perceptioninformation specificity is on the uniqueness of the relationship between perception and the appropriate physical observables. The latter emphasis is especially important in fashioning a scientific strategy: In the absence of a single-valued function relating perception to information, the scientist has not yet identified the appropriate information (Barac-Cikoja \& Turvey, 1991, 1995; Burton \& Turvey, 1990; Fitzpatrick et al., 1994; Turvey \& Carello, 1995).

\section{Attention in Haptic Perceptual Instruments}

The capabilities of dynamic touch have led to a characterization of the system as a kind of measurement device, a haptic perceptual instrument (Burton \& Turvey, 1991; Carello, Fitzpatrick, Domaniewicz, Chan, \& Turvey, 1992; Runeson, 1977; Solomon \& Turvey, 1988; Solomon et al., 1989b). Four criterial properties have been identified for such a device, and they are especially germane to its role in selective haptic attention. To perceive a property $y$, the haptic perceptual instrument detects a property $x$. In so doing, it must be: (1) smart in exploiting as $x$ a law-based aspect of the situation, in this case, the invariant nature of $I_{i j} ;(2)$ determinate in producing single-valued mappings of $x \rightarrow y$; (3) scaled to the actual metric values of $y$ despite the fact that $x$ is in very different units; and (4) soft in that it is assembled temporarily for a specific measurement task (and need not be assembled over a specific anatomical structure). What is especially striking is the richness of this instrument in seemingly identical circumstances of wielding a rod under different intentions. It softly assembles to exploit $I_{i j}$ differently depending on the measurement goal or intention, producing 1:1 maps for each intention, appropriately scaled for each.

The strong form of the assertion that $I_{i j}$ underlies the perception of magnitudes and directions by dynamic touch is that only properties that affect $I_{i j}$ should be perceivable; those that do not affect $I_{i j}$ should not be perceivable. A corollary of this assertion has guided the present research: In order for different properties of the same configuration to be perceivable - that is, in order for selective attention to be successful-there must be a tensor-based means for directing attention. As we have argued, $I_{y z}$ plays that role in perceiving partial length. If there is not such a means, intended properties will not be 
separable. For example, it appears that whereas the orientation of the branch of an $L$ can be perceived, the different orientations of two branches off the same stem cannot be distinguished (Pagano \& Turvey, 1992). Although the two branches produce an asymmetry in the mass distribution that affects the perceived orientation of the whole object, the parts cannot be discerned. In contrast, the length of a rod and the distance of a surface it strikes can be separated (Carello et al., 1992; Chan \& Turvey, 1991), as can the size and distance of an aperture (Barac-Cikoja \& Turvey, 1995) and the separate lengths of two branches being wielded simultaneously (Turvey, Carello, Fitzpatrick, Pagano, \& Kadar, 1996).

In investigations of touch that do not involve $I_{i j}$, unattended properties also vary in the degree to which they influence the perception of attended properties. It has been noted, for example, that perceiving the shape of a planar surface is not influenced by the texture of that surface, whereas perception of its hardness is so influenced (Klatzky, Lederman, \& Reed, 1989). In such investigations, these kinds of influences have been considered interference effects in which one property is said to "intrude" on another and the appeal is to theoretical frameworks of the percept-percept coupling or perceptual integration sort (e.g., Ashby \& Townshend, 1986; Epstein, 1982; Garner, 1974; Hochberg, 1974). Given that interference does not occur among all properties and need not be symmetrical for those that do interfere, the underpinnings of interference are sought in compatibilities between properties or the exploratory procedures (Lederman \& Klatzky, 1987) that are used to extract them (Klatzky et al., 1989; Reed, Lederman, \& Klatzky, 1990). The compatibilities among properties may differ when the objects are 3-dimensional rather than planar because of the ease or difficulty of executing appropriate exploratory procedures simultaneously (Lederman, Klatzky, \& Reed, 1993). For dynamic touch, however, whether or not a dimension of variation will influence a given perceived property depends simply on how that dimension affects $I_{i j}$, not on how that dimension is itself perceived. Indeed, dimensions that might be thought to intrude on perceived length (e.g., object mass or diameter) can be held constant or made to vary inversely with length and not diminish the basic reliance on $I_{i j}$ (Fitzpatrick et al., 1994). Similarly, the mediation of perceived partial length by perceived whole length or perceived grip location is unnecessary in light of a fuller appreciation of $I_{i j}$.

\section{Shifting Attention}

A thoroughgoing account of selective haptic perception must solve an additional puzzle. We now know that given $I_{i j}$ and the intention to perceive the length of the rod in front of the hand, the haptic perceptual system detects the relationship between moments and products. But what if the intention were to perceive the length of the rod behind the hand? This is readily accomplished (Turvey et al., 1996) and leads to a puzzle: There is only one $I_{i j}$ but it must somehow be the basis of perceiving partial lengths in both directions. This could be accomplished if, for example, $I_{y z}$ were multiplied by -1 whenever the short piece is behind the hand. The tensorial strategy demands that this solution be grounded in the rotational dynamics of wielding, however, and not in a post hoc convention. The requisite intrinsic two-valuedness is provided by the attitude spinor, which is an additional feature of the invariant of rotational dynamics detected by dynamic touch (Turvey \& Carello, 1995; Turvey et al., 1996). Briefly, a spinor $S$ expresses the orientation or attitude of the inertia ellipsoid, a geometric representation of the tensor, relative to the hand. It does so in terms of a directed rotation; its multiplicative inverse $-S$ specifies the rotation through the complementary angle. $S$ and $-S$, therefore, are equivalent rotations with opposite senses. This is the essential two-valuedness of spinors arising from the fact that each spinor represents a unique oriented rotation (Hestenes, 1986). An important feature for attention phenomena is that spinors can be calculated and entered into the multiple regression. Although the details of spinor theory are beyond the scope of the present investigation, the example underscores the central theme we have been pursuing: To the extent that a property $y$ is perceived by dynamic touch, a specifying property $x$ must be available in the rotational dynamics (cf. Pagano et al., 1996, for perceived grip).

\section{Conclusion}

Given the argued-for lawfulness of informationenvironment specificity and perception-information specificity, we should address deviations from metrical precision. The entire enterprise of perceiving length by dynamic touch has been directed at understanding the informational basis for that ability. The puzzle is that the requested property, length, is a geometric quantity that cannot affect the tissues of the body. The informational basis must be with respect to dynamic quantities; that basis has been shown consistently to be $I_{i j}$. This necessarily means that observers will sometimes be "wrong" in their perceptions of actual metrical length. But they are wrong in an important way. It is not that they have no idea what the length is - they have a very definite impression. They are simply constrained by the inertia tensor. We have repeatedly said that participants in these experiments produced length estimations that were in the appropriate range for the actual lengths they were perceiving. This means that they did not simply order rod lengths relative to one another. If that were the case, they could as easily have ordered them within a truncated and short range, a truncated and long range, or used the full length allowed by our apparatus (in excess of $2 \mathrm{~m}$ ). Rather, the perceived lengths produced by participants were those that would be expected on the basis of the mapping between actual lengths and the tensor. (A rationale for the particular values and signs of the exponents on $I_{x x}$ and $I_{z z}$ is provided in Fitzpatrick et al., 1994).

Of course, observers show variability relative to each other and in an individual's responses to a given config- 
uration over its repetitions in an experiment. Given what is being asked of them--"move this surface so it looks as far away as this rod feels," "respond as if you were holding the rod at its end," "perceive a property in isolation that you usually detect in ongoing activity"- this is to be expected. Perceivers are, after all, dynamical systems for which one hallmark property is fluctuation (which underlies flexibility). This certainly does not undercut the claim that haptic perception is essentially "in the right ballpark." Moreover, the exponents on the components of $I_{i j}$ that characterize perceived length are nearly identical (in size and sign) to those that characterize actual length. Bingham (1993) has suggested that a limited tolerance on the variation in perceptual responses indicates that the scaling that is being demonstrated is definite rather than absolute or simply relative (see also Peck, Jeffers, Carello, \& Turvey, in press). Perception of partial length by wielding is similarly characterized by a definite scaling. The definiteness comes from the fact that the informational basis is specificational.

\section{REFERENCES}

Amazeen, E. L., \& Turvey, M. T. (1996). Weight perception and the haptic "size-weight illusion" are functions of the inertia tensor. Journal of Experimental Psychology: Human Perception \& Performance, 22, 213-232.

ASHBY, F. G., \& TownSHEND, J. T. (1986). Varieties of perceptual independence. Psychological Review, 93, 154-179.

BaraC-Cikoja, D., \& Turvey M. T. (1991). Perceiving aperture size by striking. Journal of Experimental Psychology: Human Perception \& Performance, 17, 330-346.

Barac-Cikoja, D., \& Turvey, M. T. (1995). Does perceived size depend on perceived distance? An argument from extended haptic perception. Perception \& Psychophysics, 57, 216-224.

Bingham, G. P. (1993). Perceiving the size of trees: Forms as information about scale. Journal of Experimental Psychology: Human Perception \& Performance, 19, $1139-1161$

BORISENKO, A. I., \& TARAPOV, I. E. (1979). Vector and tensor analysis with applications. New York: Dover.

Burton, G., \& Turvey, M. T. (1990). Perceiving the lengths of rods that are held but not wielded. Ecological Psychology, 2, 294-324.

Burton, G., \& Turvey, M. T. (1991). Attentionally splitting the mass distribution of hand-held rods. Perception \& Psychophysics, 50, 129-140.

Burton G., Turvey M. T., \& Solomon H. Y. (1990). Can shape be perceived by dynamic touch? Perception \& Psychophysics, 48, 477487.

Carello, C., Fitzpatrick, P., Domaniewicz, I., Chan, T.-C., \& TurVEY, M. T. (1992). Effortful touch with minimal movement. Journal of Experimental Psychology: Human Perception \& Performance, 18, 290-302.

Carello C., Fitzpatrick P., \& Turvey M. T. (1992). Haptic probing: Perceiving the length of a probe and the distance of a surface probed. Perception \& Psychophysics, 51, 580-598.

Chan, T.-C. (1994). Haptic perception of partial-rod lengths with the rod held stationary or wielded. Perception \& Psychophysics, $\mathbf{5 5}$, $551-561$

Chan, T.-C., \& Turvey, M. T. (1991). Perceiving the vertical distances of surfaces by means of a hand-held probe. Journal of Experimental Psychology: Human Perception \& Performance, 17, 347-358.

EPSTEIN, W. (1977). What are the prospects for a higher-order stimulus theory of perception? Scandinavian Journal of Psychology, 18, $164-171$

Epstein, W. (1982), Percept-percept coupling. Perception, 11, 75-83. Fitzpatrick, P., Carello, C., \& Turvey, M. T. (1994). Eigenvalues of the inertia tensor and exteroception by the "muscular sense." Neuroscience, 60, 551-568.

GARNER, W. R. (1974). The processing of information and structure. Hillsdale, NJ: Erlbaum

Gibson J. J. (1959). Perception as a function of stimulation. In S. Koch (Ed.), Psychology: A study of a science (Vol. 1, pp. 456-501). New York: McGraw-Hill.

GiBson, J. J. (1966). The senses considered as perceptual systems. Boston: Houghton Mifflin.

GiBSON, J. J. (1979). The ecological approach to visual perception. Boston: Houghton Mifflin.

Hayward, V. (1992). Physical modeling applies to physiology, too. Behavioral \& Brain Sciences, 15, 342-343.

HestenEs, D. (1986). New foundations for classical mechanics. Dordrecht: Kluwer.

HochberG, J. (1974). Higher-order stimuli and inter-response coupling in the perception of the visual world. In R. B. MacLeod \& H. L. Pick (Eds.), Essays in honor of J. J. Gibson (pp. 17-39). Ithaca, NY: Cornell University Press.

KLATZKY, R. L., LeDERMAN, S., \& REED, C. (1989). Haptic integration of object properties: Texture, hardness, and planar contour. Journal of Experimental Psychology: Human Perception \& Performance, 15, 45-57.

Lederman S., \& Klatzky, R. L. (1987). Hand movements: A window into haptic object recognition. Cognitive Psychology, 19, 342-368.

Lederman, S., Klatzky, R. L., \& Reed, C. (1993). Constraints on haptic integration of spatially shared object dimensions. Perception, 22, 723-743

Mark, L. S., Balliett, J. A. Craver, K. D., Douglas, S. D., \& Fox, T. (1990). What an actor must do in order to perceive the affordance for sitting. Ecological Psychology, 2, 325-366.

MoON, P., \& SPENCER, D. E. (1986). Theory of holors. Cambridge: Cambridge University Press.

NeISSER, U., \& BeCKLEN, R. (1975). Selective looking: Attending to visually specified events. Cognitive Psychology, 15, 480-494.

Padsha, S. M., \& Stein, R. B. (1973). The bases of tremor during a maintained posture. In R. B. Stein, K. G. Pearson, R. S. Smith, \& J. B. Redford (Eds.), Control of posture and locomotion (pp. 415419). New York: Plenum

Pagano, C. C., Carello, C., \& Turvey, M. T. (1996). Exteroperception and exproprioperception by dynamic touch are different functions of the inertia tensor. Perception \& Psychophysics, 58, 1191-1202.

Pagano, C. C., Fitzpatrick, P., \& Turvey, M. T. (1993). Tensorial basis to the constancy of perceived object extent over variations of dynamic touch. Perception \& Psychophysics, 54, 43-54.

Pagano, C. C., Kinsella-Shaw, J. M., Cassidy, P. E., \& Turvey, M. T. (1994). Role of the inertia tensor in haptically perceiving where an object is grasped. Journal of Experimental Psychology: Human Perception \& Performance, 20, 276-284.

Pagano, C. C., \& Turvey, M. T. (1992). Eigenvectors of the inertia tensor and perceiving the orientation of a hand-held object by dynamic touch. Perception \& Psychophysics, 52, 617-624.

Pagano, C. C., \& Turvey, M. T. (1993). Perceiving by dynamic touch the distances reachable with irregular objects. Ecological Psychology, 5, 125-151.

Pagano, C. C., \& Turvey, M. T. (1995). The inertia tensor as a basis for the perception of limb orientation. Journal of Experimental Psychology: Human Perception \& Performance, 21, 1070-1087.

Peck, A., Jeffers, R. G., Carello, C., \& Turvey, M. T. (in press). Haptically perceiving the length of one rod by means of another. Ecological Psychology.

Reed, C., Lederman, S., \& KlatzKY, R. L. (1990). Haptic integration of planar size with hardness, texture, and planar contour. Canadian Journal of Psychology, 44, 522-545.

Riccio, G. E. (1993). Information in movement variability about the qualitative dynamics of posture and orientation. In K. M. Newell \& D. M. Corcos (Eds.), Variability and motor control (pp. 317-357). Champaign, IL: Human Kinetics.

RUNESON, S. (1977). On the possibility of "smart" perceptual mechanisms. Scandinavian Journal of Psychology, 18, 172-179.

Saltzman, E. (1979). Levels of sensorimotor representation. Journal of Mathematical Psychology, 20, 91-163. 
SOLOMON, H. Y., \& TURVEY, M. T. (1988). Haptically perceiving the distances reachable with hand-held objects. Journal of Experimental Psychology: Human Perception \& Performance, 14, 404-427.

SOLOMON, H. Y., TURVEY, M. T., \& BurToN, G. (1989a). Gravitational and muscular variables in perceiving rod extent by wielding. Ecological Psychology, 1, 265-300.

Solomon, H. Y., Turvey, M. T., \& Burton, G. (1989b). Perceiving extents of rods by wielding: Haptic diagonalization and decomposition of the inertia tensor. Journal of Experimental Psychology: Human Perception \& Performance, 15, 58-68.

SPENCER, D. (1991). Vector and tensor analysis. In R. G. Lerner \& G. L. Trigg (Eds.), Encyclopedia of physics (pp.1334-1337). New York: VCH Publishers.

TANGHERLINI, F. R. (1991). Moment of inertia. In R. G. Lerner \& G. L. Trigg (Eds.), Encyclopedia of physics (pp. 767-770). New York: VCH Publishers.

Turvey, M. T., Burton, G., Amazeen, E. L., Butwill, M., \& CARELLO, C. (1995). Perceiving the width and height of a hand-held object by dynamic touch. Manuscript submitted for publication.

Turvey, M. T., Burton, G., Pagano, C. C., Solomon, H. Y., \& RuneSON, S. (1992). Role of the inertia tensor in perceiving object orientation by dynamic touch. Journal of Experimental Psychology: Human Perception \& Performance, 18, 714-727.

Turvey, M. T., \& Carello, C. (1995). Dynamic touch. In W. Epstein \& S. Rogers (Eds.), Handbook of perception and cognition: Vol. 5. Perception of space and motion (pp. 401-490). New York: Academic Press.

Turvey, M. T., Carello, C., Fitzpatrick, P., Pagano, C. C., \& KADAR, E. (1996). Spinors and selective dynamic touch. Journal of Experimental Psychology: Human Perception \& Performance, 22, $1113-1126$.

\section{NOTES}

1. We use the symbol $I_{i j}$ for the inertia tensor rather than the symbol I. $I_{i j}$ is preferred by most authors because the index notation is the basis for tensor transformations, tensor algebra, and tensor equations (e.g., Borisenko \& Tarpov, 1979; Moon \& Spencer, 1986). The entries by Tangherlini (1991) and by Spencer (1991) in the Encyclopedia of Physics summarize, respectively, the modern perspectives on the inertia tensor and tensors in general.

2. Wielding need not be restricted to movements about the wrist; results are the same for wielding at the wrist, elbow, shoulder, or all three. It is simply that the inertia tensor is defined relative to the wrist, a point that remains a fixed distance from the object during wielding (Pagano, Fitzpatrick, \& Turvey, 1993).

3. These values can be found in a correction of Chan's (1994) Table 3 (which contained incorrect placements of the decimal point) that appeared in 1995. The corrected table appears to have retained one incorrect value (whole $L_{\mathrm{p}}$ for a $50-\mathrm{cm}$ rod with a rear mass).

4 . The multiple regressions are done in $\log$-log coordinates because of the nonlinearities introduced by the squared terms in the equations for moments of inertia. In order to put $I_{y z}$ in the $\log$ scale, its negative numbers necessitate using the $\log (1+x)$ formulation.

\section{APPENDIX}

A sonic movement digitizer (Science Accessories Associates, Stratford, CT) was used to record motions of rods held under the conditions of Experiment 1 . A volunteer held four of the rods (the $90-\mathrm{cm}$ rod was too long to fit in the digitizer volume) with the 15-, 25-, and 35-cm grips, in random order. As in Experiment 1, the forearm was supported and the rods were occluded from view. She was instructed to hold each as still as possible for $30 \mathrm{sec}$ (the approximate duration of a trial in Experiment 1). A signal from an emitter attached to the front of each rod was sampled at a rate of $90 \mathrm{~Hz}$ in the $x, y$, and $z \mathrm{di}-$

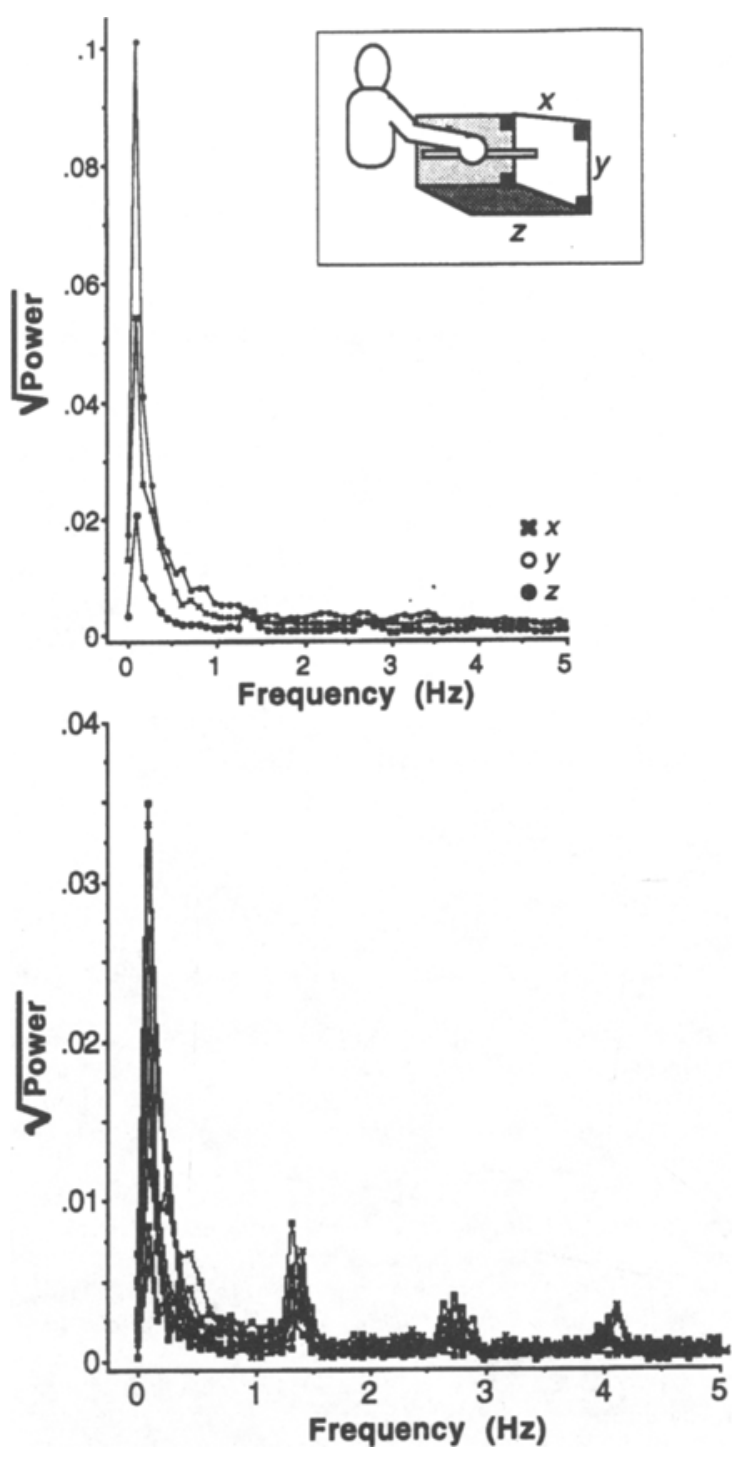

Figure A1. Top: power spectra in the $x, y$, and $z$ directions as a function of frequency. (The inset shows how these directions were defined.) Data from three grips and four rod lengths are averaged (the square root was taken to fit all three spectra on the same plot). Bottom: the power spectra of $z$ for all rods and grips show the peaks at a frequency corresponding to cardiac pulse and its harmonics, $2 f$ and $3 f$.

rections (see Figure $\mathrm{A} 1$, inset). The power spectra for the time series for each direction were determined. They are shown in Figure Al (top), averaged over the 12 combinations. The major peak at a frequency of $.09 \mathrm{~Hz}$ reflects the initial sway when the experimenter released the rod. Especially apparent in the $z$ spectra for all rods and grips (Figure A1, bottom) is the secondary peak at $1.3 \mathrm{~Hz}$ and its harmonics which reflect periodicities of cardiac pulse ( 80 bps for this individual).

(Manuscript received July 12, 1995 ; revision accepted for publication January 29,1996 .) 